\title{
A Review of Current Challenges in Production Planning
}

\author{
P. Szármes \\ Széchenyi István University, Multidisciplinary Doctoral School \\ of Engineering Sciences \\ Egyetem tér 1, H-9026 Győr, Hungary \\ e-mail: peter.szarmes@sze.hu
}

\begin{abstract}
For manufacturing companies growing customer expectations, shortening product life cycles and increasing product variant numbers mean great challenges. Overcoming these is a major task for production planning, which is responsible for coordinating all business processes directly related to manufacturing. This paper presents important activities of production planning giving an integrative overview, and presents the digital factory concept with special attention to problems and their possible solutions. It concludes with challenges still waiting to be resolved and future development trends.
\end{abstract}

Keywords: production planning, digital factory, manufacturing process optimization

\section{Introduction}

Today's rapidly changing business environment with ever increasing customer expectations creates great challenges for manufacturing companies: they must quickly adapt their products, manufacturing processes and even their technologies to current demands and new technical solutions. Failing to do so may result in a loss of market share and eventually in financial troubles since manufacturing happens to be their most expensive and time-consuming activity.

Developing, testing and introducing new production processes and technologies is a major task of production planning. Production planning is a planning and coordinating activity embracing the entire manufacturing process: it involves not only planning but also keeping close contact with machine and technology suppliers, quality managers and manufacturing engineers in order to control and support the whole manufacturing process.

On this department hinges to a great extent the competitiveness of manufacturing companies. Not only technical constraints have to be considered here, but time, quality and economic factors as well. Production planning must ensure that the company carries out its manufacturing operations with modern and appropriate technology and welltrained workforce through effective and efficient processes. 
The digital factory concept is an integrated approach in production planning, using various tools to enhance the design and manufacturing processes of products. It can be also seen as a business initiative that aims to manage information and collaboration in order to solve manufacturing problems and facilitate volume and variant production, which are determining factors in decreasing costs and increasing sales revenue [1].

\section{Production planning in general}

Production planning is a complex activity bridging the gap between product design and production and involves all activities related to setting up a production system with all the resources and processes [2]. The benefits from a good product design can be lost easily if delays or cost overruns occur in production due to inefficient, expensive and unpredictable manufacturing processes.

Production costs are determined mostly by product characteristics but production process properties also have a significant impact. Since there is a constant price pressure in the market, cost cutting measures have to start in the product design phase, but then production processes must be planned with cost-consciousness as well [3].

Manufacturing companies must therefore steadily develop flexible and efficient production processes. New methods and production techniques must be introduced constantly to keep pace with external developments and satisfy the customer needs for customized and personalized products, faster deliveries, better service offerings and so on.

In sections 3-6 major parts of production planning (product engineering, production engineering, logistics optimization, operative production control) are examined in a more detailed way with special attention to the digital factory concept. Section 7 reviews challenges and difficulties in the implementation of the digital factory concept and gives a short description of a promising new type of manufacturing execution systems: the holonic manufacturing execution system.

\section{Product engineering}

The increasing involvement of customers in the design (or even in the concept phase) of the product they are going to purchase requires a stronger collaboration between design and marketing people, customers and suppliers through co-development or simply through web interfaces [4]. This customization or even personalization coupled with other services is more and more important in satisfying individual customer needs.

The consequence of this co-design or co-creation is a growing number of variants and thus increasing complexity on the production lines. There are however design principles to tackle this problem, like modularization and product families. Products are often built from standardized modules whose designs are reused and updated. A product family is a group of similar products from similar components, which can be built on flexible production lines with minimal setting modifications [5].

The digital factory concept strives to streamline and optimize this complex product engineering process through various IT tools, like CAD systems which also allow collaboration among all teams working on product design and manufacturing. Perhaps 
the most important element of product engineering is product lifecycle management (PLM).

PLM aims to manage all aspects of product engineering from design inception through manufacturing and maintenance to its disposal. It helps to enforce company specific engineering workflows, what can increase product flexibility, facilitate design and manufacturing concurrency through reuse of components, avoid design flaws as early as possible, enable collaboration among design and manufacturing engineers, suppliers and other partners, and integrate different IT tools into a coherent process [6].

\section{Production engineering}

Production engineering or production planning focuses on the optimization of manufacturing processes. It encompasses numerous elements from layout design through material flow optimization, production line and process optimization to the simulation of machine operations. The general objectives are to shorten time-to-market and time-to-volume, improve production efficiency through optimizing necessary investments in machines, buffer levels and scrap ratio.

Computer planning, modelling and simulation techniques enable a thorough and detailed analysis that ensure that design problems and waste in production processes are discovered before the company ramps up for production and also help to start efficient volume production sooner.

\subsection{Layout planning}

There are special CAD tools for factory layout planning where a detailed factory model with all its production lines can be built from predefined elements (conveyors, cranes, containers and even machines). With three-dimensional objects a 3D factory model is the result, enabling virtual walks, measurements and inspections in a not yet existing factory.
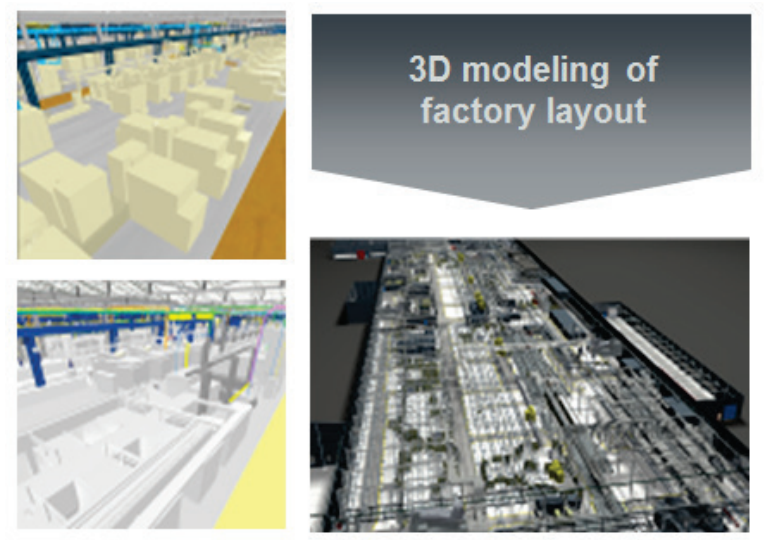

Figure 1. HLS 3D layout (preliminary, detailed, final plans) [7] 
3D modeling facilitates earlier design changes for a machine or the production line (if necessary), and in this way modeling enables the timely and cost efficient implementation of projects (see Fig. 1).

\subsection{Simulation of production processes}

Simulation is a crucial part of digital manufacturing and is used as a planning aid for analyzing and planning complex manufacturing and logistics systems. The rather static view of the planned factory or production line in the CAD system can be extended by simulation software. Simulation can create a dynamic view of the production process based on machine parameters (e.g. loading, unloading and processing times) and material flow parameters (distances, frequencies etc.).

These simulation models allow the analysis of production line variants, what-if analyses and thus help to optimize material flow, resource utilization and logistics before even investing in the components of the new production line. Bottlenecks and problems can be detected in advance avoiding costly corrections during volume production. Simulation models can also be used to optimize an already running production line trying out planned measures in a virtual reality.

\subsection{Simulation of manufacturing operations}

Simulation of manufacturing operations means to simulate operation steps in processing $\mathrm{NC} / \mathrm{CNC}$ machines and robotic workcells in order to calculate operating cycle times, error rates, resource utilization, work-in-process and buffer sizes. It also enables to detect collisions of manufacturing instruments or robots. Robotic work cells are complex equipment where the kinematics of robot components should be analyzed to generate optimal sequence of operations, avoid collisions and check whether robotic arms can reach the points of products to be processed. These tools can greatly help and accelerate the creation of robot programs [6].

\subsection{Simulation of human resources}

Today there are software tools even for simulating manual operations performed by human operators in order to optimize execution times and prevent work-related injuries. These software tools support the detailed design of operations, calculate execution time, make ergonomic analyses and generate work instructions.

\section{Logistics optimization}

The optimization of production systems is a very complex multi-criteria decisionmaking task encompassing layout optimization, fine-tuning of certain system parameters and generating production program [9]. On a strategic level the whole supply chain must be considered since it is an interdependent network of business partners and its characteristics may heavily influence tactical and operational decisions.

Layout optimization means the exact configuration of production line components (machines, conveyors, containers etc.) This activity was already mentioned in the previous section about production engineering since it is subject to technical constraints 
before logistical ones and should be decided early upon because major changes can prove quite costly afterwards.

Fine-tuning of parameters involves selecting optimal production and logistical characteristics of the production system, e.g. number of production and logistics employees, number and type of forklift trucks, inventory levels, frequency of deliveries from or to the warehouse etc. [9] These parameters can be modified more or less easily even in a running system, unlike configuration changes for an already existing production line.

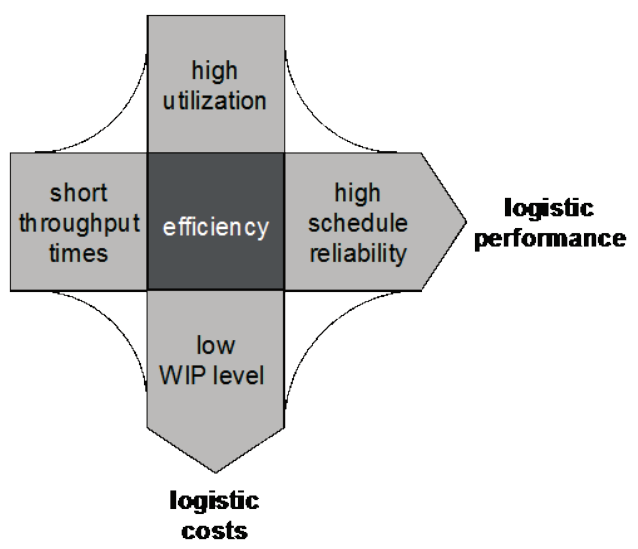

Figure 2. Objectives in production logistics [10]

When generating actual daily or weekly production programs decisions must be made which order to be processed on which production line/machine (mapping) and in which sequence and time (sequencing and scheduling). The production program has a high impact on delivery time and delivery reliability, which are important buying criteria beside price and quality. High delivery reliability and short delivery times require high schedule reliability and short throughput times, and logistics costs should also be optimized as Fig. 2 shows [10].

These logistics objectives are conflicting (it is called the scheduling dilemma) since it is not possible to maximize the utilization of a system while also minimizing throughput times. High utilization demands higher work-in-progress levels, which lead to longer throughput times, and also reduce schedule reliability. Hence a rational trade-off must be reached between these objectives to ensure a satisfactory level for all of them [10].

These decisions can be optimized using methods from operations research and it can be shown that many resource allocation problems can be formulated as special Markov decision processes [11]. Markov decision problems can be solved by dynamic programming, which solves complex problems by breaking them down into simpler sub problems. 


\section{Operative production control}

Production management system ensures that the planned production program is properly executed on the shop floor and enables capturing and sharing real-time manufacturing data for control and analysis. This system helps to improve order allocation on production lines, to make necessary program adjustments more easily, improve quality, reduce work-in-progress and scrap costs and creates better transparency about production processes [6].

Product and production tracking technologies (e.g. RFID technologies) can automatically gather data and provide a detailed real-time perspective about manufacturing and logistics operations [12]. The real-time data from the shop floor about operations, equipment status, scrap products, work-in-progress levels enables rapid problem detection and intervention in production processes, supports various analyses for improving efficiency and helps to create more realistic simulations.

The products themselves can become important control elements but this requires steady access to their relevant properties stored on their RFID chips. The Internet of Things (IoT), a relatively new paradigm means "connectivity to anything anytime" [13]. It integrates several technologies: identification and tracking, wired and wireless sensor and actuator networks, embedded intelligence for smart objects. The Internet of Things may revolutionize manufacturing processes and help to realize the full potential of the digital factory concept. The ultimate goal is to create manufacturing systems whose elements have cognitive capabilities [14].

\section{Challenges and future developments in production planning}

A key prerequisite for the digital factory concept is the integration of IT tools supporting product design, production engineering and planning, simulation and shop floor control. It can be mostly accomplished by data integration via a central data warehouse, but it also requires interoperability between various software components and networks, and information transparency across different business partners and their IT tools. This integration and sharing of information links the enterprise resource planning system and other planning systems to the operative production control system and this system to the network of machines, sensors and actuators on the factory floor. These linkages are the essence of the digital manufacturing concept [15].

However these IT tools in the developmental, design, and planning stages are so numerous, and often differ from company to company across the supply chain, that creating all the necessary interfaces is an almost impossible and very costly task. The required standardized networking of these tools is therefore hardly feasible. In addition to this problem of compatibility the problems of version and data management should be solved as well. These difficulties nevertheless generate a strong motivation to create industry-independent open standards and frameworks. These standards with the potential benefits inherent in the paradigm of the Internet of Things may overcome the difficulties mentioned above and fully realize the digital factory concept.

There is much research on a new type of manufacturing execution system called the holonic manufacturing execution system. Its coordination and control mechanisms are inspired by natural systems, i.e. food foraging behavior in ant colonies [16]. This 
control by distributed intelligence or swarm intelligence is very different from hierarchical control structures in traditional systems, and it can be realized using IoT technologies.

The holonic system is based on holons, which are single independent units (similar to agents) communicating with each other, thus also functioning as parts of a larger system. In the PROSA system architecture three types of holons (product holon, resource holon and order holon) have been defined. Resource holons describe the manufacturing resources containing data about manufacturing physics and all necessary control systems. These holons are responsible for resource scheduling and allocation. Product holons are abstractions of products with product design and product manufacturing information. Order holons represent orders for products. The three types of holons together establish a distributed intelligence system for manufacturing control [16].

These systems are still under development but promise numerous benefits. They show a fractal design, which repeats itself on the various levels of a production network, lending scalability, robustness and high adaptability to manufacturing control.

\section{Conclusion}

Production planning plays a crucial role in the competitiveness of manufacturing companies and it might gain even greater significance in the future as digital factory concept and the Internet of Things paradigm unfolds. It is almost an art to create large and complex manufacturing systems from people, machines, materials and processes. These systems have to be not only efficient but also robust and adaptable. Building such systems requires a holistic view with steady learning and incessant developing because technology progresses rapidly while customer needs are also changing.

Embracing new concepts, methods and technologies, however, brings no automatic benefits. These tools must be tuned to a company's specific methods of operation, integrated into its business processes and aligned with its goals and objectives to realize their full potential.

\section{References}

[1] Schraft RD, Bierschenk S: Digitale Fabrik und ihre Vernetzung mit der realen Fabrik. Zeitschrift für wirtschaftlichen Fabrikbetrieb, Vol. 100, No. 1-2, pp. 14-18, 2005.

[2] Dangelmaier W: Fertigungsplanung - Planung von Aufbau und Ablauf der Fertigung. Springer, Berlin, 2001.

[3] Menges R: Frühzeitige Produktbeeinflussung und Prozessabsicherung. Zeitschrift für wirtschaftlichen Fabrikbetrieb, Vol. 100, No. 1-2, pp. 25-31, 2005.

[4] Tomiyama T, Gu P, Jin Y, Lutters D, Kind C, Kimura F: Design Methodologies: Industrial and Educational Applications. CIRP Annals - Manufacturing Technology, Vol. 58, No. 2, pp. 543-565, 2009.

DOI: $10.1016 /$ j.cirp.2009.09.003 
[5] Váncza J, Monostori L, Lutters D, Kumara SR, Tseng M, Valckenaers P, Van Brussel H: Cooperative and responsive manufacturing enterprises. CIRP Annals Manufacturing Technology, Vol. 60, No. 2, pp. 797-820, 2011.

DOI: $10.1016 /$ j.cirp.2011.05.009

[6] Kühn W: Digital factory - simulation enhancing the product and production engineering process. Proceedings of the 2006 Winter Simulation Conference IEEE, pp. 1899-1906, 2006.

DOI: $10.1109 /$ WSC.2006.322972

[7] Audi Hungaria Motor Kft., Production Planning Department

[8] Verbund der Deutschen Automobilhersteller: Ausführungsanweisung:

Ablaufsimulation in der Automobil- und Automobilzuliefererindustrie, V. 2.0. VDA, 2008.

[9] Kapp R, Löffler B, Wiendahl HP, Westkämper E: The logistics bench: Scalable logistics simulation from the supply chain to the production process. CIRP Journal of Manufacturing Systems, Vol. 34, pp. 5-54, 2005.

[10] Wiendahl HP: Fertigungsregelung: Logistische Beherrschung von Fertigungsabläufen auf Basis des Trichtermodells. Carl Hanser, München, 1997.

[11] Monostori L, Csáji BC, Kádár B, Pfeiffer A, Ilie-Zudor E, Kemény Z, Szathmári M: Towards adaptive and digital manufacturing. Annual Reviews in Control, Vol. 34, No. 1, pp. 118-128, 2010. DOI: $10.1016 /$ j.arcontrol.2010.02.007

[12] Monostori L, Kemény Z, Ilie-Zudor E, Szathmári M, Karnok D: Increased Transparency Within and Beyond Organizational Borders by Novel IdentifierBased for Enterprises of Different Size. CIRP Annals - Manufacturing Technology, Vol. 58, No. 1, pp. 417-420, 2009.

[13] ITU Internet Reports: The Internet of Things. Geneva: Int. Telecommunication Union, 2005.

[14] Zäh MF, Reinhart G, Ostgathe M, Geiger F, Lau C: A Holistic Approach for the Cognitive Control of Production Systems. Advanced Engineering Informatics, Vol. 24, No. 3, pp. 300-307, 2010.

DOI: $10.1016 /$ j.aei.2010.05.014

[15] Kapp R, Aldinger L, Westkämper E: Real-time Factory Cockpit System. Implementation and Assurance of Economic Transformability, Glasgow: Proceedings of the 20th Computer-Aided Production Engineering, pp. 99-108, 2007.

[16] Valckenaers P, Van Brussel H: Holonic Manufacturing Execution Systems. CIRP Annals - Manufacturing Technology, Vol. 54, No. 1, pp. 427-432, 2005. DOI: $\underline{10.1016 / \mathrm{S} 0007-8506(07) 60137-1}$ 